\title{
Game Edukasi Matematika dan Pengenalan Angka Menggunakan Teknologi Kinect dengan Metode Gesture Recognition
}

\author{
Galuh Prakoso ${ }^{1}$, Ina Agustina ${ }^{2}$, Fauziah $^{3}$ \\ ${ }^{1}$ galuhprakoso17@gmail.com, ${ }^{2}$ ina.agustina@ civitas.unas.ac.id, ${ }^{3}$ fauziah@ civitas.unas.ac.id
}

Program Studi Teknik Informatika, Fakultas Teknologi Komunikasi dan Informatika, Universitas Nasional

\begin{abstract}
Technology has been used in several sectors on a massive basis, especially in the education sector. But because of the less interactive learning method, the students' learning interest becomes decreased when going to the math lesson. Gesture recognition is a technology that allows a digital device to detect or receive input in the form of user movement through the camera and execute commands according to the input given. The purpose of this research is the making of educational game about mathematics and recognition of numbers with hardware kinect $X B O X 360$ using gesture recognition method to organize and move objects in Unity 3D made using Blender software. From the results of research can be concluded that the best fps obtained from some trials is 60fps. The ideal distance between kinect and user when playing this game is 1.5 to 2 meters with an average decreace of 8,9 fps per 0,25 meter. The average computational time to read the movement from the user is 1035,9 ms. And by using random question's script, the question variables can be randomly scrambled without any repetition.
\end{abstract}

Abstrak-Teknologi telah digunakan dalam beberapa sektor secara masif, terutama dalam sektor pendidikan. Tetapi karena metode pembelajaran yang kurang interaktif, minat belajar para siswa menjadi turun ketika akan mengikuti pelajaran matematika. Gesture recognition adalah teknologi yang memungkinkan sebuah perangkat digital mendeteksi atau menerima input berupa gerakan pengguna melalui kamera dan melaksanakan perintah sesuai dengan input yang diberikan. Tujuan dari penelitian ini adalah pembuatan game edukasi tentang matematika dan pengenalan angka dengan hardware kinect XBOX 360 menggunakan metode gesture recognition untuk mengatur dan menggerakkan objek didalam software Unity 3D yang dibuat menggunakan software Blender. Dari hasil penelitian dapat disimpulkan bahwa fps terbaik yang didapatkan dari beberapa percobaan adalah 60fps. Jarak ideal antara kinect dan pengguna dalam memainkan game ini adalah 1,5 sampai 2 meter dengan rata - rata penurunan 8,9 fps per 0,25 meter. Rata - rata waktu komputasi untuk membaca gerakan dari pengguna adalah 1035,9 ms. Dan dengan menggunakan script acak soal, variabel - variabel soal dapat teracak secara random tanpa ada pengulangan.

Kata Kunci- Kinect, Pengenalan Gestur, Matematika, Game, Edukasi, Blender, Unity 3D

\section{PENDAHULUAN}

Di bidang pendidikan, ada banyak kesulitan dan hambatan. Salah satu dari masalah ini adalah kurangnya pemahaman tentang matematika selama masa kanak - kanak, dimana guru perlu mencari lebih banyak teknik untuk membuat siswa memahami matematika dengan cara yang mudah[1].

Gesture recognition adalah metode yang sudah banyak digunakan dalam industri pembuatan film maupun pembuatan game, para pengembang game menggunakan metode ini supaya game yang mereka buat menjadi lebih interaktif dan lebih hidup karena interaksi antara game dan pengguna semakin banyak. Jika game yang dibuat menggunakan input biasa, pergerakan yang dapat dibuat terbatas pada alat input yang digunakan, namun jika menggunakan Kinect pergerakan yang dapat dibuat sebagai input dapat divariasikan sedemikian rupa. Pada penelitian ini, penulis memanfaatkan metode Gesture Recognition menggunakan hardwareKinect XBOX 360 sebagai alat input dalam game. Kinect merupakan alat input berupa sensor pergerakan yang dibuat oleh Microsoft yang berbasis webcam tambahan, yang memungkinkan pengguna untuk berinteraksi dengan game yang mereka mainkan tanpa harus menggunakan alat input lain seperti mouse, atau keyboard (opsional)[2].

Pada penelitian sebelumnya, aplikasi dibuat menggunakan hardwareKinect, dan software Unity 3D dengan bahasa pemrograman C\# serta program - program pembantu seperti 3DS Max 2011 untuk pembuatan objek 3 dimensi dan Adobe Auditon 3.0 untuk pengolahan suara. Game yang dihasilkan 
pada penelitian ini berbasis semi 3D dimana masih ada sebagian fitur 2D yang digunakan, seperti tombol, gambar, dan keterangan objek[3].

Pada penelitian lainnya, pada setiap level, pengguna harus menggunakan gerak untuk menyelesaikan soal aritmatika yang dihasilkan secara acak. Pergerakan yang dilakukan termasuk beberapa gerakan sederhana seperti mengangkat tangan kanan atau kiri untuk menggerakkan karakter ke kanan atau kiri[4].

Pada fase pengujian lainnya, dilakukan proses pengujian jarak sejauh $0,0.5,1,1.5,2,2.5,3,3.5$, dan 4 meter sebanyak 10 kali pengujian untuk mendeteksi bagaimana tingkat kestabilan kontrol. Dan diapatkan kesimpulan bahwa aplikasi yang dibuat dapat mendeteksi pengguna dengan jarak 1.5 meter hingga 3 meter, dengan jarak optimal pengguna dengan kinect adalah 2 meter[5].

Pada penelitian sebelumnya, dilakukan pengujian waktu komputasi aplikasi dalam membaca gerakan pengguna dengan penginputan data sebanyak 3 kali dan didapatkan hasil rata rata waktu komputasi sebesar 1085,877778 ms.

Berdasarkan penelitian - penelitian sebelumnya, terdapat beberapa masalah yang terjadi dalam proses pembuatan game menggunakan teknologi kinect antara lain apakah soal yang ditampilkan dapat muncul secara acak, berapa lama waktu komputasi yang dibutuhkan untuk membaca gerakan dari pengguna dan apakah jarak pengguna dengan sensor mempengaruhi sensitivitas dari sensor kinect terhadap game.

Berdasarkan latar belakang tersebut, penulis ingin membuat sebuah game dengan judul "Game Edukasi Matematika dan Pengenalan Angka Menggunakan Teknologi Kinect Dengan Metode Gesture Recognition" yang bertujuan untuk merancang game edukasi matematika dan pengenalan angka semi 3 dimensi menggunakan teknologi kinect dengan metode Gesture Recognition dan kinect hanya dapat membaca gerakan tangan dari pengguna, memanfaatkan fitur List pada Unity 3D untuk merancang soal supaya dapat ditampilkan secara acak dalam setiap level yang berbeda, dan melihat apakah perbedaan jarak antara pengguna dan kinect berpengaruh terhadap kestabilan dan sensitivitas sensor didalam game yang dirancang[6].

\section{A. Kerangka Penelitian}

\section{METODE PENELITIAN}

Penelitian dimulai dengan proses pengumpulan data. Setelah data terkumpul, selanjutnya storyboard dibuat sebagai acuan dalam proses pembuatan game. Setelah storyboard dibuat, proses pembuatan model 3D dan perancangan script di Unity 3D dapat dilakukan. Tahap selanjutnya adalah mengintegrasikan Kinect dengan Unity 3D menggunakan script yang sudah dibuat. Jika Kinect dapat terhubung maka dilanjutkan dengan proses perancangan desain game dan mengintegrasikan script pada setiap scene. Bila tidak akan kembali ke proses perancangan script. Proses testing dilakukan untuk memastikan bahwa game dapat digunakan dengan baik

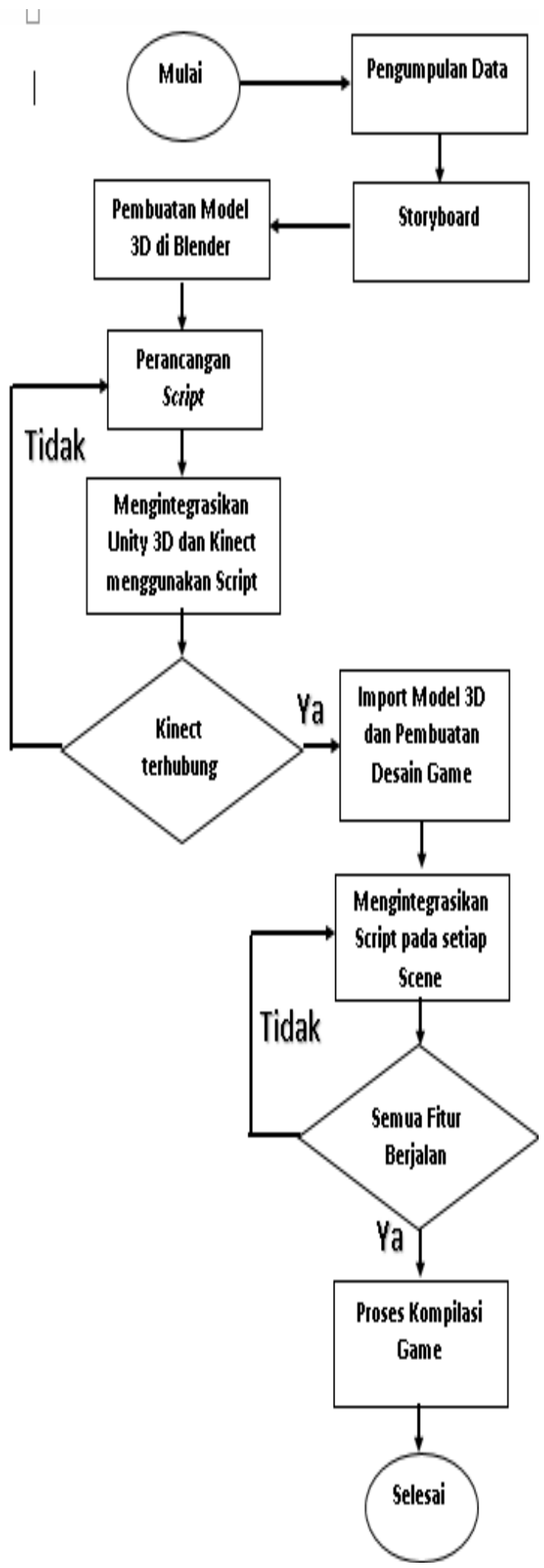

Gambar 1 Flowchart Kerangka Penelitian 


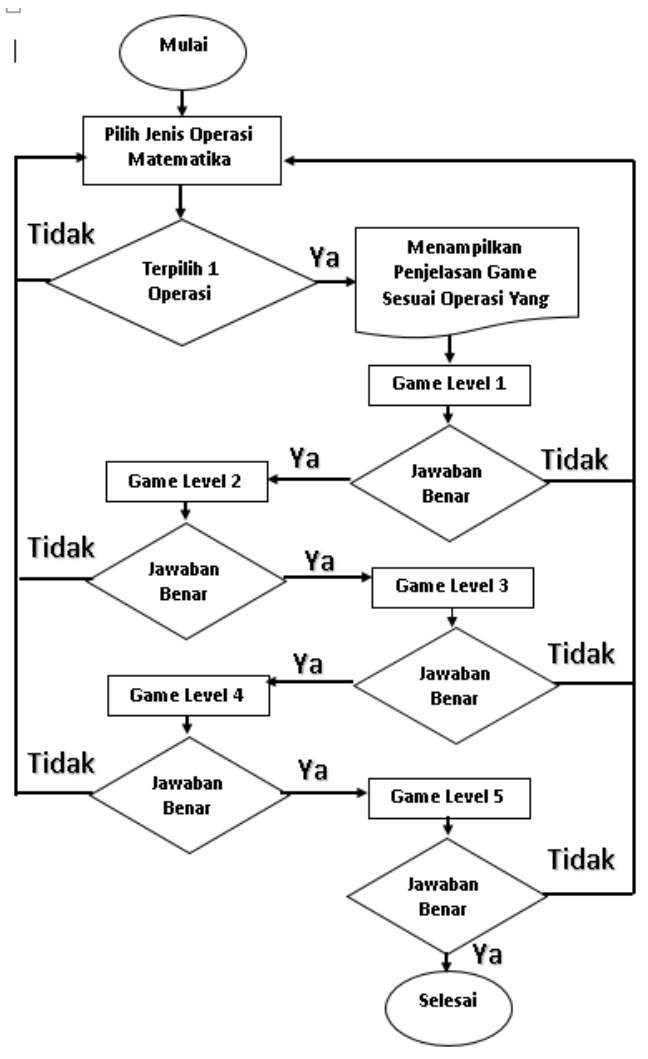

Gambar 2 Flowchart Perancangan Game

Game terdiri 20 level yang terbagi atas 4 sub operasi matematika. Game dimulai dengan memilih jenis operasi yang tersedia di halaman utama, yaitu pertambahan, pengurangan, pembagian, dan perkalian. Jika salah satu operasi telah dipilih, game akan menampilkan penjelasan mengenai operasi matematika yang dipilih serta cara melakukan permainan. Jika user dapat menjawab setiap soal pada level dengan benar, maka user akan masuk ke level selanjutnya. Jika user tidak dapat menjawab soal dengan benar, maka user akan kembali ke menu awal

\section{B. Gesture Recognition}

Gesture Recognition adalah teknologi bahasa yang bertujuan untuk menafsirkan gerakan manusia melalui algoritma matematika. Gesture dapat berasal dari pergerakan tubuh manusia tetapi umumnya berasal dari tangan atau wajah.

Pada penelitian sebelumnya, dikatakan bahwa lingkungan belajar berbasis permainan tidak hanya menekankan pada pearncangan sistem pembelajaran berbasis permainan namun juga berfokus pada interaksi manusia dan komputer di lingkungan tersebut.

Dalam proses perancangan game ini pergerakan tangan dari pengguna akan dibaca oleh game sebagai input melalui sensor infrared yang terdapat pada Kinect XBOX 360. Pengguna harus berada dalam jarak tertentu agar sensor infrared pada Kinect dapat membaca pergerakan tangan dari pengguna tersebut.

\section{Analisis Kebutuhan Perangkat}

Dalam penelitian ini penulis menggunakan beberapa perangkat keras dan lunak pada proses perancangan game, yaitu sebagai berikut:

- Perangkat Lunak

Tabel 1 Spesifikasi Perangkat Lunak

\begin{tabular}{|l|}
\hline \multicolumn{1}{|c|}{ Nama Perangkat } \\
\hline Unity 3D 5.5.4 \\
\hline Adobe Photoshop CS6 \\
\hline Adobe Audition CS6 \\
\hline Blender 2.77a \\
\hline Mono Develop \\
\hline Kinect SDK \\
\hline Windows 10 Home 64-bit \\
\hline
\end{tabular}

- Perangkat Keras

Tabel 2 Spesifikasi Kinect

\begin{tabular}{|c|c|}
\hline Jenis Fitur & Spesifikasi \\
\hline \multirow{2}{*}{ Sensor } & $\begin{array}{c}\text { Sens or Monokrom IR } \\
\text { CMOS }\end{array}$ \\
\hline & Kamera RGB \\
\hline \multirow{3}{*}{ Area Deteksi } & $\begin{array}{l}\text { Area Deteksi Vertical : } \\
43^{\circ}\end{array}$ \\
\hline & $\begin{array}{c}\text { Area Deteksi } \\
\text { Horizontal : } 57^{\circ}\end{array}$ \\
\hline & $\begin{array}{l}\text { Jarak Sensor: } 1,2- \\
3,5 \mathrm{~m}\end{array}$ \\
\hline \multirow{2}{*}{ Skeleton Tracking } & Aktif : 2 Orang \\
\hline & Pasif : 6 Orang \\
\hline Versi & Kinect 1.8 \\
\hline
\end{tabular}


Tabel 3 Spesifikasi Perangkat Keras

\begin{tabular}{|c|c|}
\hline Perangkat & Spesifikasi \\
\hline Prosesor & $\begin{array}{c}\text { Intel Core } \mathrm{i} 5 \text { 7200U } \\
2.5 \mathrm{GHz}\end{array}$ \\
\hline RAM & 4 Gigabyte \\
\hline VGA & 2 Gigabyte \\
\hline
\end{tabular}

\section{HASIL DAN PEMBAHASAN}

\section{A. Fitur Program}

Ketika program dijalankan, pengguna akan melihat tampilan splash screen.

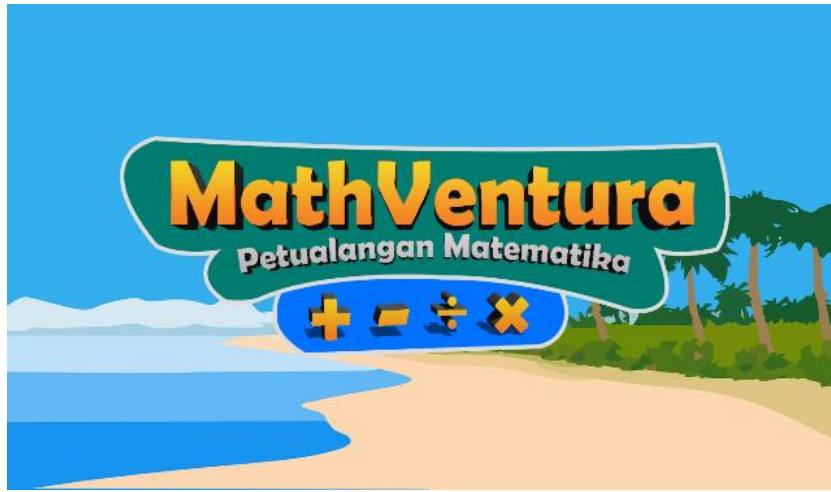

Gambar 3 Tampilan Splash Screen

Setelah itu akan muncul tampilan utama yang terdiri dari button pilihan jenis operasi matematika, button tentang, button pilihan level, dan button keluar. Ketika pengguna menyentuh tombol level, pengguna akan masuk ke permainan level sesuai dengan jenis operasi matematika yang dipilih.

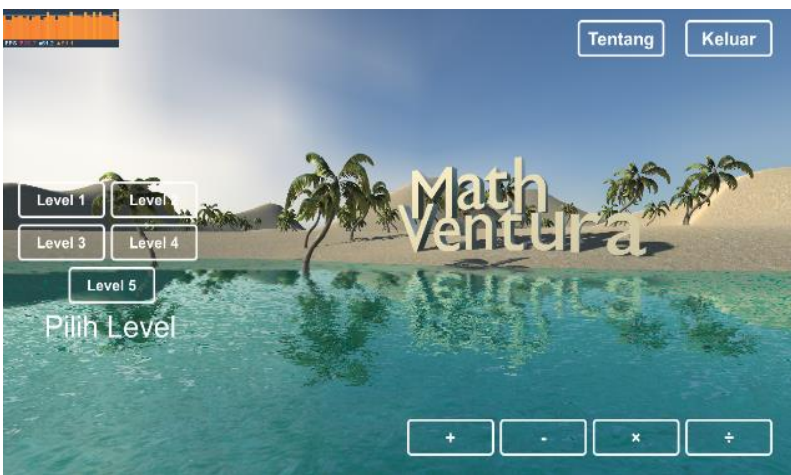

Gambar 4 Tampilan Menu Utama

Jika pengguna menyentuh tombol tentang profil, maka tampilan tentang profil perancang game akan tampil.

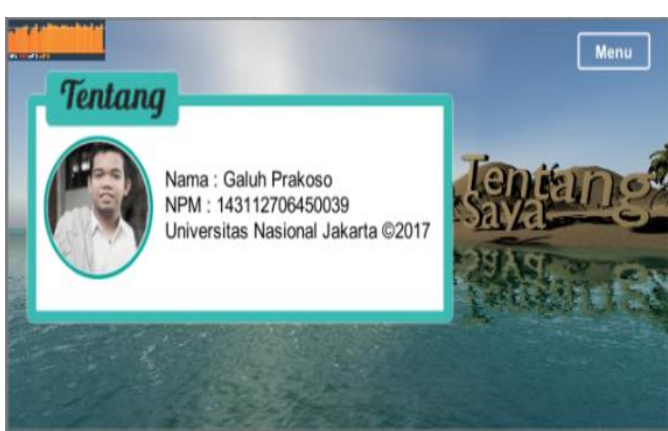

Gambar 5 Tampilan Menu Tentang Penulis

Jika level 1 terpilih maka akan tampil seperti berikut.

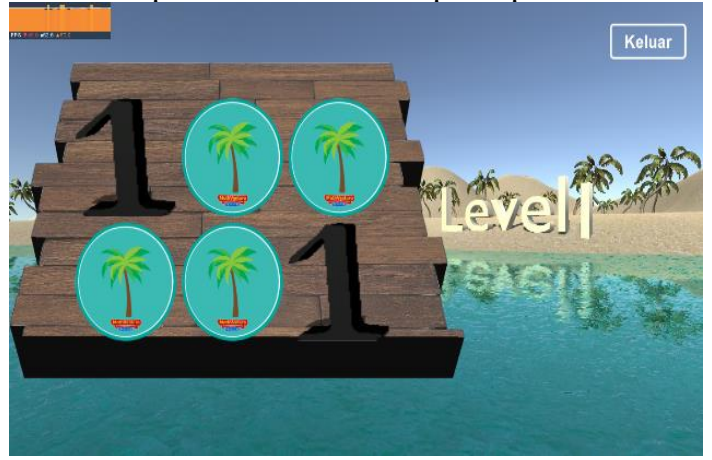

Gambar 6 Tampilan Level 1

Pengguna harus menemukan angka yang sama dibalik tombol - tombol yang ditampilkan untuk menyelesaikan level.

Jika level 2 terpilih maka akan tampil seperti berikut.

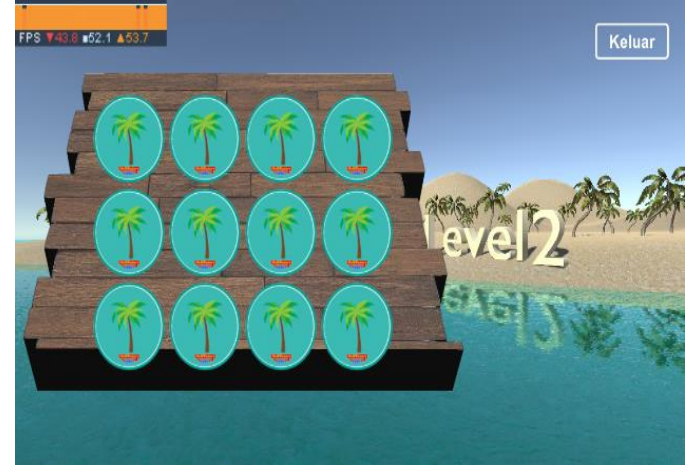

Gambar 7 Tampilan Level 2

Jika level 3 terpilih maka akan tampil seperti berikut.

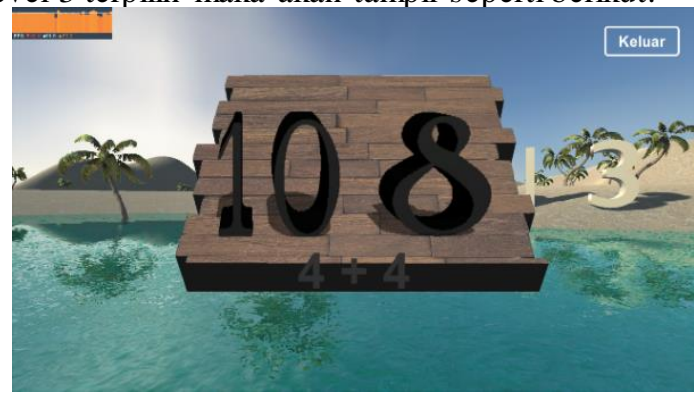

Gambar 8 Tampilan Level 3 
Jika level 4 terpilih maka akan tampil seperti berikut.

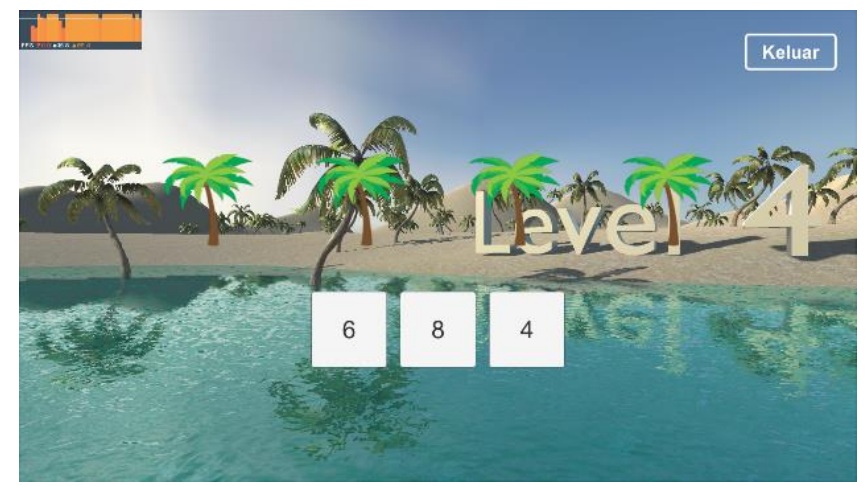

Gambar 9 Tampilan Level 4

Jika level 5 terpilih maka akan tampil seperti berikut.

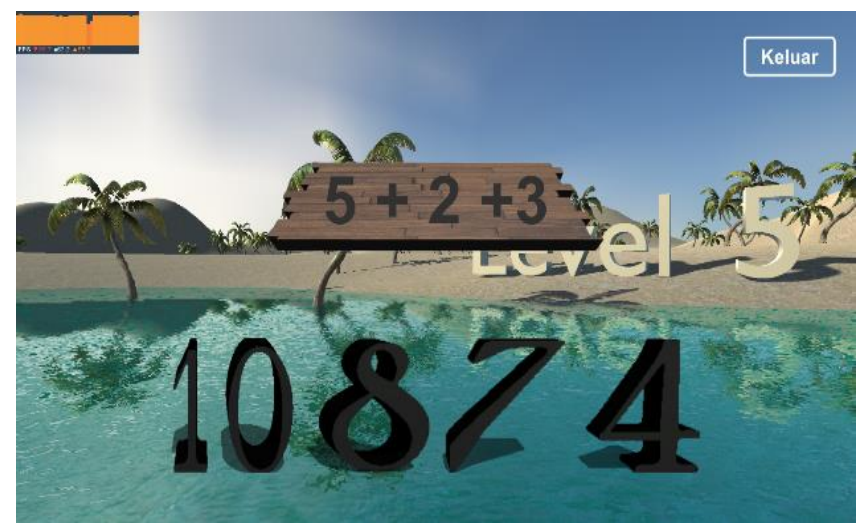

Gambar 10 Tampilan Level 5

Pada tiap level terhadap tombol Back untuk kembali ke menu utama.

\section{B. Pengujian Terhadap Device}

Pada tahap ini, pengujian program dilakukan pada 4 device dengan spesifikasi yang berbeda.

Tabel 4 Spesifikasi Perangkat

\begin{tabular}{|l|c|c|c|}
\hline \multicolumn{1}{|c|}{ Tipe } & $\begin{array}{c}\text { Sistem } \\
\text { Operasi }\end{array}$ & CPU & RAM \\
\hline $\begin{array}{l}\text { Lenovo } \\
\text { IdeaPad } \\
310\end{array}$ & $\begin{array}{c}\text { Core i5 } \\
7200 \mathrm{U}\end{array}$ & $\begin{array}{c}2.5 \\
\mathrm{GHz}\end{array}$ & $\begin{array}{c}4 \\
\text { Gigabyte }\end{array}$ \\
\hline $\begin{array}{l}\text { Dell } \\
\text { Inspiron } \\
\text { N4110 }\end{array}$ & $\begin{array}{c}\text { Core i5 } \\
2430 \mathrm{M}\end{array}$ & $\begin{array}{c}2.4 \\
\mathrm{GHz}\end{array}$ & $\begin{array}{c}4 \\
\text { Gigabyte }\end{array}$ \\
\hline $\begin{array}{l}\text { Asus } \\
\text { X550Z }\end{array}$ & AMD APU & 2.7 & $\begin{array}{c}4 \\
\text { FX-7600P }\end{array}$ \\
\hline $\begin{array}{l}\text { GHz } 14- \\
\text { AF115A }\end{array}$ & AMD A6 & $2 \mathrm{GHz}$ & $\begin{array}{c}4 \\
\text { Gigabyte }\end{array}$ \\
\hline
\end{tabular}

Tabel 5 Hasil Pengujian Device

\begin{tabular}{|l|c|c|c|}
\hline \multicolumn{1}{|c|}{ Tipe } & $\begin{array}{c}\text { Kinect } \\
\text { Terhub } \\
\text { ung }\end{array}$ & $\begin{array}{c}\text { Puzzle } \\
\text { Acak }\end{array}$ & FPS \\
\hline $\begin{array}{l}\text { Lenovo } \\
\text { IdeaPad } \\
310\end{array}$ & Berhasil & $\begin{array}{c}\text { Berhasi } \\
1\end{array}$ & $50-60 f p s$ \\
\hline $\begin{array}{l}\text { Dell } \\
\text { Inspiron } \\
\text { N4110 }\end{array}$ & Berhasil & $\begin{array}{c}\text { Berhasi } \\
1\end{array}$ & $48-55 f p s$ \\
\hline $\begin{array}{l}\text { Asus } \\
\text { X550Z }\end{array}$ & Berhasil & $\begin{array}{c}\text { Berhasi } \\
1\end{array}$ & $55-60 f p s$ \\
\hline $\begin{array}{l}\text { HP 14- } \\
\text { AF115AU }\end{array}$ & Berhasil & $\begin{array}{c}\text { Berhasi } \\
1\end{array}$ & $37-50 f p s$ \\
\hline
\end{tabular}

Berdasarkan tabel diatas, program dapat berjalan dengan baik dengan minimal processor $2 \mathrm{GHz}$ dan ukuran ram $4 \mathrm{~GB}$.

\section{Pengujian Random Index Soal}

Pengujian dilakukan dengan metode White Box Testing, white box adalah pengujian yang didas arkan pada pengecekan terhadap detail perancagan menggunakan struktur kontrol dari desain program secara prosedural untuk membagi pengujian ke dalam beberapa kasus pengujian. Script yang digunakan dalam melakukan pengacakan soal adalah sebagai berikut.

\begin{tabular}{|l|}
\hline void acakpuzzle(List<Sprite $>$ list $)\{$ \\
for $($ int $\mathrm{i}=0 ; \mathrm{i}<$ list.Count; $\mathrm{i}++)$ \\
$\{$ Sprite temp = list $[\mathrm{i}] ;$ \\
int randomindex = Random.Range (i, \\
list.Count); \\
list [i] = list [randomindex]; \\
list [randomindex] = temp; $\}$
\end{tabular}

$$
\text { Gambar } 11 \text { Script Random Soal }
$$

Jikaposisi soal tidak diacak, maka posisi awal soal adalah sebagai berikut:

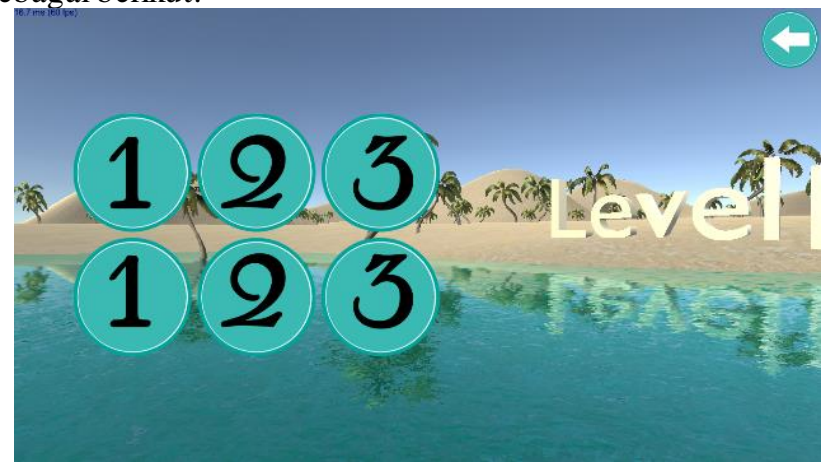

Gambar 12 Posisi Awal Soal 
Percobaan pengacakan soal dilakukan sebanyak 10 kali untuk mengetahui apakah soal teracak secara random atau tidak.

Tabel 6 Hasil Percobaan Acak Soal

\begin{tabular}{|c|c|}
\hline Percobaan & $\begin{array}{c}\text { Hasil Random Index } \\
\text { Puzzle }\end{array}$ \\
\hline 1 & 211233 \\
\hline 2 & 112332 \\
\hline 3 & 233121 \\
\hline 4 & 211332 \\
\hline 5 & 321132 \\
\hline 6 & 312321 \\
\hline 7 & 322113 \\
\hline 8 & 112323 \\
\hline 9 & 332112 \\
\hline 10 & 313221 \\
\hline
\end{tabular}

Dari tabel diatas dapat disimpulkan bahwa dengan menggunakan script soal dapat diacak dengan baik secara random.

\section{Pengujian FPS (Frame Per Second)}

Pengujian dilakukan dengan cara melihat dan menentukan FPS yang didapatkan didalam game dengan menggunakan asset Mini Profiler untuk merekam FPS terbaik dan terburuk didalam game dan mengukur jarak pengguna dengan kinect.

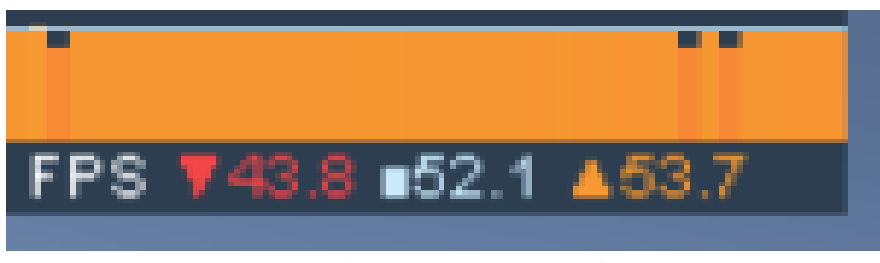

Gambar 13 Mini Profiler

Tabel 7 Spesifikasi Perangkat PengujianFPS

\begin{tabular}{|c|c|c|c|}
\hline Tipe & $\begin{array}{c}\text { Sistem } \\
\text { Operasi }\end{array}$ & CPU & RAM \\
\hline $\begin{array}{c}\text { Lenovo } \\
\text { IdeaPad } \\
310\end{array}$ & $\begin{array}{c}\text { Core i5 } \\
7200 \mathrm{U}\end{array}$ & $\begin{array}{c}2.5 \\
\mathrm{GHz}\end{array}$ & $\begin{array}{c}4 \\
\text { Gigabyte }\end{array}$ \\
\hline
\end{tabular}

Perhitungan FPS dilakukan dengan cara menjalankan game sebanyak 10 kali dengan jarak 1 meter s/d 3.25 meter. Setelah 10 kali percobaan, akan diambil jumlah fps terbaik dan terburuk.
Tabel 8 Hasil Percobaan Frame Per Second

\begin{tabular}{|c|c|c|}
\hline $\begin{array}{c}\text { Jarak } \\
\text { Pengguna } \\
\text { Terhadap } \\
\text { Kinect }\end{array}$ & $\begin{array}{c}\text { FPS } \\
\text { Terburuk }\end{array}$ & FPS Terbaik \\
\hline 1 meter & 56 & 60 \\
\hline 1.25 meter & 53 & 60 \\
\hline 1.5 meter & 50 & 60 \\
\hline 1.75 meter & 55 & 60 \\
\hline 2 meter & 50 & 60 \\
\hline 2.25 meter & 47 & 60 \\
\hline 2.5 meter & 47 & 57 \\
\hline 2.75 meter & 45 & 56 \\
\hline 3 meter & 43 & 53 \\
\hline 3.25 meter & 40 & 49 \\
\hline
\end{tabular}

Berdasarkan standar baru yang dibuat oleh ATSC (Advance Television Systems Committee), FPS terbaik yang didapatkan dalam standar video $1080 \mathrm{p}$ berada pada 50 sampai 60 frames per second.

Tabel 9 ATSC Standard

\begin{tabular}{|c|c|c|c|}
\hline \multicolumn{2}{|c|}{ Resolution } & \multirow{2}{*}{$\begin{array}{c}\text { Aspect } \\
\text { Ratio }\end{array}$} & $\begin{array}{c}\text { Frame Rate } \\
(\mathbf{H z})\end{array}$ \\
\cline { 1 - 2 } Vertical & Horizontal & $16: 9$ & $59.9450,60$ \\
\hline 1080 & 1920 & & \\
\hline
\end{tabular}

Berdasarkan pengujian FPS didapatkan rata - rata pengurangan FPS sebesar 8,9 fps per 0,25 meter dan dapat disimpulkan bahwa untuk mendapatkan FPS yang ideal yaitu antara 50 - 60 FPS, game sebaiknya dimainkan dalam jarak 1,5 - 2 meter dari kinect dengan jarak ideal 2 meter.

\section{KESIMPULAN DAN SARAN}

Dari hasil pengujian game edukasi matematika terlihat fitur program berjalan dengan baik. Sedangkan untuk pengujian bagian device dapat berjalan minimal processor $2 \mathrm{GHz}$ dan ukuran ram 4 GB. Selanjutnya pengujian random index Soal dengan jumlah percobaan 10. Hasil penujian yang diperoleh selama script soal diacak berjalan dengan baik. Dalam pengujian frame per second diperoleh jarak maksimal dalam permainan 1,5 - 2 meter dari kinect. Untuk penelitian selanjutnya perlu ditambahkan level dan perlu penelitian dalam pengalaman penguna.

\section{DAFTAR PUSTAKA}

[1] Y. Chang, J. Hwang, and R. Fang, "A Joyful Kinectbased Learning System,” pp. 1028-1031, 2017.

[2] G. S. Ajie, M. A. Marpaung, A. Kurniawan, M. Suryani, I. Suryana, and E. Paulus, "The Development and Usability Testing of Game- based Learning as A Medium to Introduce Zoology to Young Learners," pp. 541-545, 2017. 
[3] A. S. T. Afandi, H. Hindersah, and A. I. Wuryandari, "Design and Implementation of Turn-Based Strategy ( TBS ) Game as Part of Service- Based Alternate Reality Game ( ARG )," pp. 0-5, 2014.

[4] F. Chao, "Application of Board Game and 3-D Components in Children' s Environmental Education," 2018 1st IEEE Int. Conf. Knowl. Innov. Invent., pp. 210213, 2018.

[5] S. Wulandari, "Safari Rangers Board Game as A Campaign Media for Endangered Animal Conservation."

[6] Z. Sun, Z. Li, and T. Nishimori, "Development and Assessment of Robot Teaching Assistant in Facilitating Learning," pp. 165-169, 2017. 
